\section{REGISTRO NACIONAL DE HISTORIAS CLÎNICAS ELECTRÓNICAS EN PERÚ}

\section{NATIONAL REGISTRY OF ELECTRONIC HEALTH RECORDS IN PERU}

\section{Leonardo Rojas Mezarina ${ }^{1, a}$, Carmen Alicia Cedamanos Medina ${ }^{1, b}$, Javier Vargas Herrera ${ }^{1,2, c}$}

Sr. Editor. Cuando un paciente acude a un establecimiento de salud, público, privado o mixto, para ser atendido, requiere contar con una historia clínica. En Perú, casi todas las historias clínicas están contenidas en papel (HCP). Si el paciente acude por primera vez a un establecimiento se procede a abrir una nueva historia clínica, lo cual implica llenar formularios en donde se registran datos (administrativos y clínicos) normalizados para una historia clínica. Pero, cuando acude en una siguiente oportunidad, no es infrecuente que no se ubique su HCP, procediéndose a repetir el ciclo de registro de datos. Asimismo, el procedimiento se repite cuando un paciente cambia de domicilio, cambia de establecimiento o se encuentra en cualquier otra parte del país. Actualmente, un paciente tiene tantas historias clínicas como establecimientos de salud visita y en un mismo establecimiento puede tener más de una.

Frente a estos inconvenientes, surge la historia clínica electrónica (HCE), que ofrece muchas ventajas frente a la HCP (Tabla 1). De acuerdo con la International Organization for Standardization (ISO), una HCE es un repositorio de datos de un paciente en un formato digital, almacenados de una manera segura y accesibles a usuarios autorizados (1), pero más que eso, es una nueva manera de almacenar y organizar la información del paciente, que junto con la interconectividad de las redes informáticas, permite que sea accesible desde cualquier espacio y en cualquier momento por los actores autorizados (pacientes, profesionales de la salud y técnicos vinculados al sector Salud), con observancia de las leyes de reserva, protección de datos personales y seguridad de acceso. En Perú, ya existen experiencias de uso de HCE con diferentes grados de desarrollo y se prevé en el corto plazo, contar con HCE en los nuevos establecimientos del Ministerio de Salud.

\footnotetext{
Ministerio de Salud. Lima, Perú.

Universidad Nacional Mayor de San Marcos. Lima, Perú.

Médico especialista en Administración de Salud; ${ }^{\mathrm{b}}$ abogada; ${ }^{\mathrm{c}}$ médico epidemiólogo.

Recibido: 28-04-15 Aprobado: 13-05-15
}

Citar como: Rojas Mezarina L, Cedamanos Medina CA, Vargas Herrera J. Registro Nacional De Historias Clínicas Electrónicas en Perú [carta]. Rev Peru Med Exp Salud Publica. 2015;32(2):395-6.
Pero, contar con HCE en todos o la mayoría de establecimientos de salud no resolvería el problema de la multiplicidad de historias clínicas si no se cuenta con una herramienta tecnológica que permita interoperar y gestionar las HCE que pudiera tener una persona en los establecimientos de salud del país. Este problema obedece a la fragmentación del sistema de salud en el Perú, en subsectores responsables de diferentes segmentos de la población (MINSA, gobiernos regionales, EsSalud, FF.AA. y FF.PP.). Al no existir una sola historia clínica o un mecanismo que la agrupe, se pierde información valiosa para actuar con responsabilidad y celeridad frente a una atención de emergencia.

Mediante Ley 30024, se creó el Registro Nacional de Historias Clínicas Electrónicas (RENHICE). Se trata de una plataforma tecnológica que permite al paciente o a su representante legal y a los profesionales de la salud que son previamente autorizados por aquellos, el acceso a la información clínica contenida en las historias clínicas electrónicas dentro de los términos estrictamente necesarios para garantizar la calidad de la atención en los establecimientos de salud y en los servicios médicos de apoyo públicos, privados o mixtos, así como, la protección de datos personales de los pacientes, establecido por ley ${ }^{(2)}$.

Una vez implementado el RENHICE, su contenido estará expresado en una base de datos de filiación de cada persona con la relación de los establecimientos de salud y de los servicios médicos de apoyo que le han brindado atención y generado una HCE. El Ministerio de Salud es el titular de dicha base de datos. Además de asegurar la disponibilidad de la información clínica contenida en las HCE para la continuidad de la atención, permitirá organizar y mantener el registro de las HCE de cada establecimiento, estandarizando los datos administrativos y clínicos, así como las funcionalidades de los sistemas que soportan las HCE. EI RENHICE debe ser entendido como un directorio electrónico en el que los profesionales de la salud de los establecimientos de salud o servicios médicos de apoyo, a través de sus sistemas de información de HCE debidamente acreditados, podrán acceder y consultar en qué otros establecimientos, un paciente tiene una HCE y permitirle acceder a esta o estas, sin que se pueda almacenar en su sistema de información (base de datos del consultante) ni en la del RENHICE, los datos de la HCE del establecimiento consultado.

Solo podrán acceder al RENHICE, los pacientes o sus representantes legales y los profesionales de la salud a quienes el paciente o sus representantes autoricen, utilizando firmas digitales. El uso de la firma digital y del certificado digital en la HCE es fundamental 
Tabla 1. Características de la historia clínica electrónica y la historia clínica manuscrita

\begin{tabular}{|c|c|c|}
\hline Variable & Historia clínica electrónica (virtual) & Historia clínica manuscrita (papel) \\
\hline Disponibilidad & $\begin{array}{l}\text { Disponible en todo momento y en varios lugares para } \\
\text { diferentes personas, de manera simultánea. }\end{array}$ & Disponible en un solo lugar físico y para una persona. \\
\hline Información & $\begin{array}{l}\text { Contiene información completa, pues tiene campos } \\
\text { obligatorios que exigen el ingreso de la información. }\end{array}$ & $\begin{array}{l}\text { La información a veces es parcial, debido a que por } \\
\text { diversas razones se omite el ingreso de información. }\end{array}$ \\
\hline Redacción & La información consignada siempre es legible. & La información consignada no siempre es legible. \\
\hline Médico tratante & Siempre se identifica al médico tratante. & $\begin{array}{l}\text { A veces no se consigna el nombre y la firma del médico } \\
\text { tratante. }\end{array}$ \\
\hline Fecha y hora & Siempre se consigna la fecha y hora. & A veces no se consigna la fecha y hora. \\
\hline $\begin{array}{l}\text { Continuidad de los actos } \\
\text { registrados }\end{array}$ & Los hechos y actos son registrados cronológicamente & $\begin{array}{l}\text { Es posible modificar la continuación temporal de los } \\
\text { sucesos. }\end{array}$ \\
\hline Calidad de la información & Ayuda a evitar tratamientos redundantes. & $\begin{array}{l}\text { No contribuye a evitar la duplicidad de información y de } \\
\text { tratamientos. }\end{array}$ \\
\hline Ingreso de datos & Es estandarizado. & Varía según el estilo de cada profesional. \\
\hline Almacenamiento & $\begin{array}{l}\text { Es más económico que el soporte físico y su reproducción } \\
\text { también. Además ocupa un espacio virtual reducido. }\end{array}$ & Es más costoso y ocupa un mayor espacio físico. \\
\hline $\begin{array}{l}\text { Seguridad de la } \\
\text { información }\end{array}$ & Es mínimo el riesgo de la información archivada (back up). & $\begin{array}{l}\text { Constantemente la información está expuesta a } \\
\text { potenciales riesgos: incendio, inundación, robo, etc. }\end{array}$ \\
\hline $\begin{array}{l}\text { Transferencia de la } \\
\text { información }\end{array}$ & $\begin{array}{l}\text { No es necesario enviarla físicamente por encontrarse siempre } \\
\text { a disposición de los usuarios autorizados (virtualmente) }\end{array}$ & Es necesario enviarla físicamente al interesado. \\
\hline $\begin{array}{l}\text { Identificación del que } \\
\text { consulta la información }\end{array}$ & $\begin{array}{l}\text { Siempre se podrá identificar al usuario que accedió a la } \\
\text { información. }\end{array}$ & $\begin{array}{l}\text { Es muy difícil llevar un registro de las personas que } \\
\text { acceden a la información. }\end{array}$ \\
\hline Durabilidad & $\begin{array}{l}\text { Permanece inalterable en el tiempo para que su información } \\
\text { pueda ser consultada. }\end{array}$ & $\begin{array}{l}\text { Sufre deterioro en el tiempo por su uso, degradación y } \\
\text { otros factores externos. }\end{array}$ \\
\hline $\begin{array}{l}\text { Reserva de la } \\
\text { información }\end{array}$ & Garantizada por mecanismos de seguridad informática. & $\begin{array}{l}\text { Garantizada por mecanismos de control del archivo, no } \\
\text { eficientes. }\end{array}$ \\
\hline
\end{tabular}

Tomado de: Congreso de la Republica. Comision de Salud y Poblacion. Dictamen 6 2012-2013. Disponible en:

http://www2.congreso.gob.pe/Sicr/TraDocEstProc/Contdoc01_2011.nsf/0/999b23f8c010279105257b2d007a2d57/\$FILE/00897DCMAY13032013.pdf

porque, de esta forma, además de autenticar su identidad, los profesionales de la salud suscribirán sus actos médicos y los pacientes autorizarán el acceso (consentimiento) a su HCE, recordemos que la firma digital ya está reglamentada en el Perú, desde el año $2008^{(3)}$. No obstante, existen personas como técnicos e ingenieros de sistemas, etc., que por su labor u oficio acceden directa o indirectamente a la información a través del RENHICE, en ese sentido, dichas personas se encuentran obligadas a guardar confidencialidad de dicha información bajo responsabilidad administrativa, civil o penal según sea el caso.

La implementación del RENHICE forma parte de las políticas de gobierno electrónico y del fortalecimiento de los sistemas de información en salud del Perú ${ }^{(4,5)}$. Resulta evidente que el uso de progresivo de la HCE en los establecimientos de salud, tanto públicos como privados, es un eje de la modernización del sector salud y contribuirá favorablemente a que todos los establecimientos de salud del país brinden un servicio de calidad en beneficio de los pacientes. Así mismo, contribuirá con la interoperabilidad en el sector salud, para el diseño y aplicación de políticas públicas que permitan el ejercicio efectivo del derecho a la salud de las personas, optimizando el uso de recursos y reduciendo la duplicidad de procedimientos de apoyo al diagnóstico que ya han sido aplicados al paciente o usuario de salud.

\section{REFERENCIAS BIBLIOGRÁFICAS}

1. Häyrinen K, Saranto K, Nykänen P. Definition, structure, content, use and impacts of electronic health records: a review of the research literatura. Int J Med Inform. 2008 May;77(5):291-304.

2. Perú, Congreso de la República. Ley No 29733. Ley de protección de datos personales. Lima: Congreso de la República; 2011.

3. Perú, Congreso de la República. Decreto Supremo 052 2008-PCM. Reglamento de la Ley de Firmas y Certificados Digitales. Lima: Congreso de la República; 2008.

4. Oficina Nacional del Gobierno Electrónico e Informática. Política Nacional de Gobierno Electrónico e Informática 2013-2017. Lima: ONGEI; 2013.

5. Curioso W. eSalud en Perú: implementación de políticas para el fortalecimiento de sistemas de información en salud. Rev Panam Salud Publica. 2014;35(5/6):437-41.

Correspondencia: Javier Vargas Herrera

Dirección: Belgrano 171 -104 Pueblo Libre, Lima, Lima

Teléfono: 945029342

Correo electrónico:jvargash@unmsm.edu.pe 